\title{
Serum ferritin as a risk factor for type 2 diabetes mellitus, regulated by liver transferrin receptor 2
}

\author{
Rui Zhang, Xinmei Huang, Yue Li, Zhiyan Yu, Yueyue Wu, Bingbing Zha, Heyuan Ding, Shufei Zang and Jun Liu \\ Department of Endocrinology, Shanghai Fifth People's Hospital affiliated to Fudan University, Minhang District, Shanghai, People's Republic of China
}

Correspondence should be addressed to S Zang or J Liu: sophiazsf@fudan.edu.cn or liu_jun@fudan.edu.cn

\begin{abstract}
Objective: The aim of this study was to evaluate the effect of TFR2 on iron storage in type 2 diabetes.

Methods: A cross-sectional study was conducted among 1938 participants from the Jiangchuan Community of Shanghai. A total of 784 participants with T2DM and 1154 normal participants (non-T2DM) were enrolled in this study. Serum ferritin, fasting blood glucose, postprandial blood glucose, and HbA1C (glycated hemoglobin A1c) levels were determined. Eighteen Wistar male rats were randomly assigned into three groups ( $n=6 /$ group): rats in a high-fat diet streptozotocin (HFD+STZ) group were fed with HFD for 4 weeks and intraperitoneally injected with streptozotocin (STZ); rats in a control group were fed with a standard diet for 4 weeks and intraperitoneally injected with buffer; rats in an STZ group were fed with a standard diet for 4 weeks and intraperitoneally injected with streptozotocin. Glucose tolerance test was performed at the end of the study. Blood samples and liver tissues were assessed for liver TFR2, blood glucose, serum ferritin, and iron levels.

Results: The mean serum ferritin level of T2DM participants was significantly higher than that of the control group (227 (140-352) vs $203.5(130.5-312) \mathrm{ng} / \mathrm{mL}, P<0.05)$. Serum ferritin level was an independent risk factor for T2DM (high ferritin group vs low ferritin group, $1.304(1.03-1.651), P<0.05)$. Diabetic rats showed reduced liver TFR2 levels, with increased serum ferritin levels.

Conclusion: T2DM participants exhibited iron disorder with elevated serum ferritin levels. Elevated serum ferritin levels in diabetic rats were accompanied by reduced liver TFR2 levels.
\end{abstract}

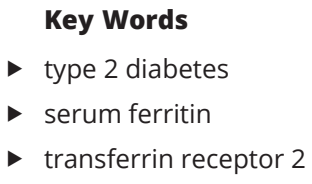

Endocrine Connections (2021) 10, 1513-1521

\section{Introduction}

There is a close association between type 2 diabetes mellitus (T2DM) and iron overload $(1,2,3)$. The association between diabetes and iron metabolism in humans was first demonstrated by clinical observations of individuals with hereditary hemochromatosis (4). Subsequently, an increasing number of studies have verified that patients with diabetes show varying iron overload, and excess iron could aggravate insulin resistance during the disease process $(5,6)$. The impact of iron overload in patients with diabetes has prompted researchers to explore the underlying mechanisms of iron accumulation in T2DM patients.

Iron is essential for fundamental metabolic processes in cells and organisms. It circulates in plasma bound to the glycoprotein transferrin, and iron metabolism is balanced by a regulatory system, which functions systemically and relies on the hormone hepcidin (HAMP). As the central regulatory molecule of systemic iron homeostasis,

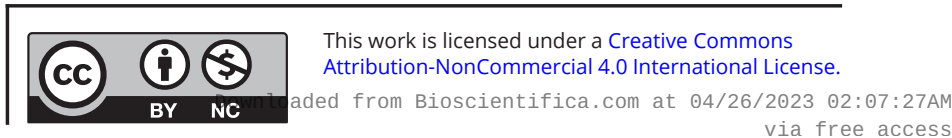


HAMP was found to decline in diabetic patients with hyperferritinemia, suggesting that HAMP plays a potential role in iron overload in T2DM. Furthermore, Wang et al. (7) confirmed such role of iron overload in diabetic rats.

However, the liver is the major iron-regulating organ that synthesizes numerous iron-related genes encoding transferrin (TF), transferrin receptor 2 (TFR2), and HAMP $(1,8,9)$. TFR2 is a TF receptor that binds to TF with a lower affinity than that of transferrin receptor 1 (TFR1) $(10,11)$. Along with the loss of functional TFR2, iron accumulates in some organs, including the liver. Therefore, TFR2 is important for iron metabolism. Previous studies have demonstrated that T2DM causes iron overload due to the downregulation of HAMP. However, whether the level of TFR2 decreases with elevated serum ferritin levels remains elusive in diabetic rats.

To evaluate the effect of TFR2 on iron storage in T2DM, this study explored serum iron metabolismrelated indicators in 1938 patients from the Jiangchuan Community of Shanghai and in streptozotocin-induced T2DM rats. Furthermore, the expression of liver-specific TFR2 was detected in T2DM rats.

\section{Materials and methods}

\section{Human subjects}

All community-dwelling participants aged $\geq 35$ years in the Jiangchuan Community of Shanghai were recruited to a platform of a chronic disease (PCD) prevention program for a routine medical checkup from March to August 2010. Those who refused to participate in the study were excluded, while included participants provided informed consent. Diabetes was confirmed by OGTT (oral glucose tolerance test) based on the diagnostic criteria recommended by the American Diabetes Association, 1997: (i) typical symptoms of diabetes (polydipsia, polyuria, polyphagia, and weight loss) plus random plasma glucose $\geq 11.1 \mathrm{mmol} / \mathrm{L}$, or (ii) FBG (fasting blood glucose) $\geq 7.0 \mathrm{mmol} / \mathrm{L}$, or (iii) OGTT $2 \mathrm{hBG}$ ( 2 hours blood glucose) $\geq 11.1 \mathrm{mmol} / \mathrm{L}$ (12).

In total, 2378 participants aged 35 to 91 years (median age, 70 years) were included in the study. Participants were excluded for the following reasons: (i) presence of any infectious disease 2 weeks prior to screening blood test (25), (ii) abnormal liver function (19), (iii) viral infection or positive carrier status (hepatitis B virus, syphilis, or HIV) (17), and (iv) iron-deficiency anemia and other disorders related to iron metabolism (67). A total of 312 participants had missing serum ferritin data because they had no blood samples. The study procedure is described in Fig. 1.

Therefore, 1938 participants (38-89 years (median age, 70 years)) were included in the final analysis. A total of 784 participants with T2DM and 1154 normal participants (non-T2DM) were enrolled in this study.

A median split (based on serum ferritin levels, cut-off level, $211.5 \mathrm{ng} / \mathrm{mL}$ ) was used to divide the participants into low and high serum ferritin groups.

Hypertension was defined as systolic blood pressure $(\mathrm{SBP}) \geq 140 \mathrm{mmHg}$ or diastolic blood pressure (DBP) $\geq 90 \mathrm{mmHg}$.

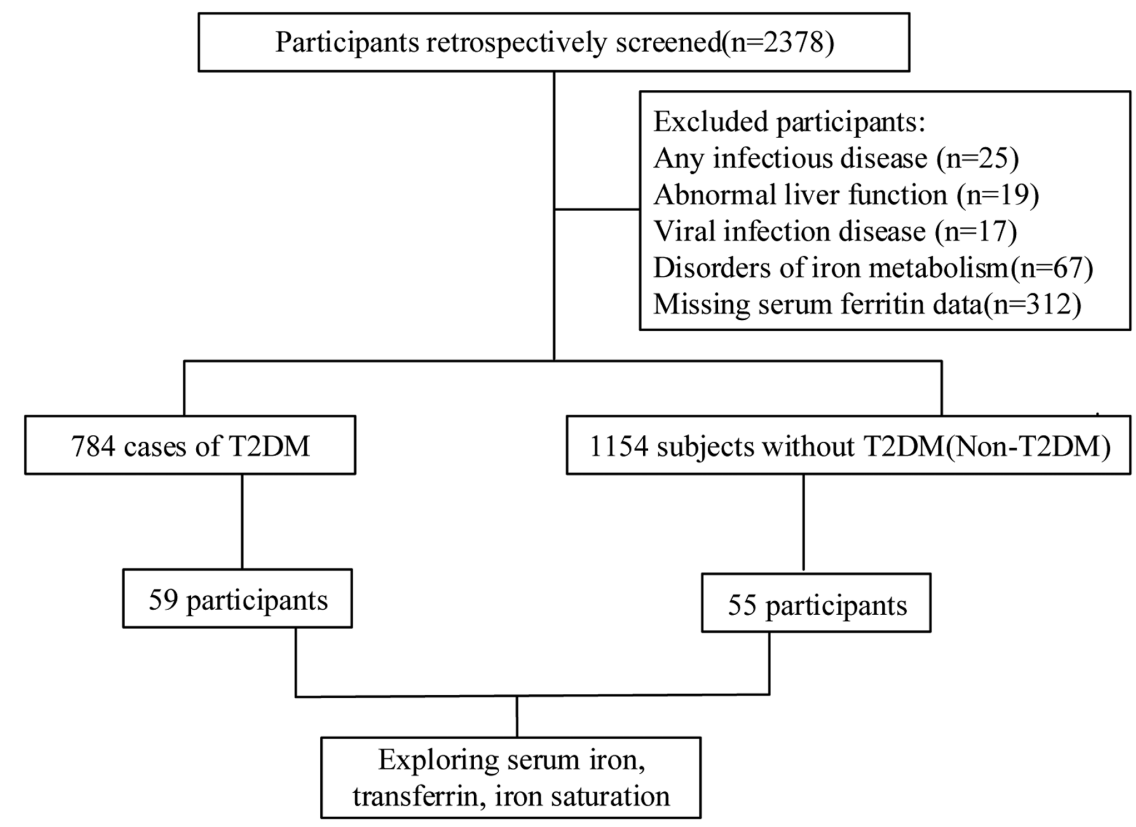

Figure 1

Flow chart of this study.

https://ec.bioscientifica.com https://doi.org/10.1530/EC-21-0316 (c) 2021 The authors Published by Bioscientifica Ltd
This work is licensed under a Creative Commons Attribution-NonCommercial 4.0 International License. ded from Bioscientifica com at 04/26/2023 02:07:27AM via free access 
Equations to estimate glomerular filtration rate (eGFR) require serum creatinine and a combination of age, sex, ethnicity, and body size as surrogates for the non-GFR determinants of serum creatinine. We used previously reported modification of diet in renal disease (MDRD) equations for individuals from China and Japan (13).

Four hundred sixty-two participants were on oral antihyperglycemic therapy or insulin, 968 were on antihypertensive medicines, and 140 were on lipid lowering therapy.

\section{Biochemical measurements}

After a $12 \mathrm{~h}$ overnight fast, blood samples were collected from the antecubital vein, and the sera were separated and stored at $-80^{\circ} \mathrm{C}$ for analyses. Glucose levels were measured using a Dimension Vista analyzer (Siemens AG). Serum ferritin levels were measured using a microparticle enzyme immunoassay with an Axsym System (Abbott Laboratories).

\section{Animal experiments}

The animal experimental protocols were approved by the Animal Ethics Committee of Shanghai Jiao Tong University, Shanghai, China (A2015072). Eighteen male Wistar rats (160-180 g) were housed individually under a controlled $12 \mathrm{~h}$ light: $12 \mathrm{~h}$ darkness cycle and temperature conditions with free access to water and a standard rat diet (SLRC Animal Feed Department, Shanghai, China). The rats were randomly divided into the following three groups and were treated as indicated: control $(n=6)$, rats were fed with a standard diet for 4 weeks and then intraperitoneally injected with the buffer; SZT group $(n=6)$, rats were fed with a standard diet for 4 weeks and then intraperitoneally injected with STZ (25 mg/kg, Sigma); high-fat diet (HFD) plus STZ group $(n=6)$, rats were fed with a HFD for 4 weeks and then intraperitoneally injected with STZ $(25 \mathrm{mg} / \mathrm{kg})$. The HFD (Research Diets, D12451, USA) contained crude protein 24/100 g (20\% kcal), carbohydrate 41/100 g (35\% kcal), fat 24/100 g (45\% kcal), and iron $3.5 \mathrm{mg} / 100$ g. The standard rat diet contained crude protein $20.5 / 100$ g (23\% kcal), carbohydrate $56.85 / 100 \mathrm{~g}(65 \% \mathrm{kcal})$, fat $4.62 / 100 \mathrm{~g}$ (11\% kcal), and iron $\geq 100 \mathrm{mg} / \mathrm{kg}$.

Body weight and blood glucose levels were monitored weekly. Glucose levels were measured using a glucometer (Gluco Touch, Roche) by pricking the rats' tails. Intraperitoneal glucose tolerance test (IPGTT) was performed during the last week of the experiment. After a $12 \mathrm{~h}$ fast, each group was injected with glucose (i.p. $2.0 \mathrm{~g} / \mathrm{kg}$ ) for IPGTT. Blood samples were collected from the tails at $0,30,60,90$, and $120 \mathrm{~min}$ to estimate blood glucose levels. After a 3-day recovery period, all rats were euthanized using pentobarbital sodium. The serum insulin levels of the rats were quantified using rat ELISA kits (TSZ, San Francisco, CA, USA). A homeostasis model assessment (HOMA) method refers to the described equation as follows: HOMA-IR $=$ FBG $(\mathrm{mmol} / \mathrm{L}) \times$ FINS $(\mathrm{mUI} / \mathrm{L}) / 22.5(7)$.

\section{Iron metabolism-related parameters}

The rat sera were harvested and stored at $-80^{\circ} \mathrm{C}$ after centrifugation at $3000 \mathrm{~g}$ for $10 \mathrm{~min}$ at $4^{\circ} \mathrm{C}$. Serum iron levels were analyzed using colorimetric analysis kits (Nanjing Jian Cheng Biotechnology Institute, Nanjing, China). Serum ferritin, TF, and HAMP levels in rats were quantitated using rat ELISA kits (anti-ferritin, anti-TF, anti-HAMP; TSZ, San Francisco, CA, USA).

\section{Western blotting}

Homogenates of the rat livers were prepared for Western blotting (WB) using anti-TFR2 and anti-glyceraldehyde-3phosphate dehydrogenase (GAPDH) antibodies (both from Abcam). The signals were quantified using densitometry and normalized to GAPDH levels. Band scan 5.0 was used to quantify the Western signals.

\section{Statistical analysis}

The data are presented as mean \pm S.D., unless otherwise noted. The $t$-test was used for between-group comparisons of continuous variables and the $\chi^{2}$ test for categorical variables. Skewed variables were expressed as median (interquartile range (IQR)), and the rank sum test was used to compare the differences between the two groups. Logistic regression analysis was performed to detect the predictability of serum ferritin levels in patients with T2DM. All statistical analyses were performed using Statistical Package for the Social Sciences (version 25.0; IBM SPSS Inc.). All $P$-values were two-tailed, and statistical significance was set at $P<0.05$.

\section{Results}

\section{Descriptive characteristics of the subjects}

Table 1 shows the distribution of demographic and clinical variables between the non-T2DM and T2DM groups. There was no significant difference in sex

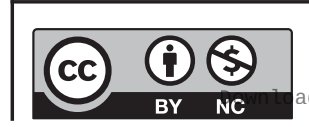

This work is licensed under a Creative Commons Attribution-NonCommercial 4.0 International License. ded from Bioscientifica.com at 04/26/2023 02:07:27AM 
Table 1 Distribution of demographic and clinical variables among the healthy control and type 2 diabetic patients.

\begin{tabular}{l}
\hline \\
\hline$n$ \\
Age (years) \\
Men $(\%)$ \\
BMI $\left(\mathrm{kg} / \mathrm{m}^{2}\right)$ \\
SBP $(\mathrm{mmHg})$ \\
DBP $(\mathrm{mmHg})$ \\
History of HBP $(\%)$ \\
TC $(\mathrm{mmol} / \mathrm{L})$ \\
TG $(\mathrm{mmol} / \mathrm{L})$ \\
HDL-c $(\mathrm{mmol} / \mathrm{L})$ \\
LDL-c $(\mathrm{mmol} / \mathrm{L})$ \\
$\mathrm{Cr}(\mu \mathrm{mol} / \mathrm{L})$ \\
eGFR $\left(\mathrm{mL} / \mathrm{min} / 1.73 \mathrm{~m}^{2}\right)$ \\
ALT $(\mathrm{u} / \mathrm{L})$ \\
HbA1C $(\%)$ \\
FBG $(\mathrm{mmol} / \mathrm{L})$ \\
$2 \mathrm{hBG}(\mathrm{mmol} / \mathrm{L})$ \\
Ferritin $(\mathrm{ng} / \mathrm{mL})$
\end{tabular}

\begin{tabular}{c}
\hline Non-T2DM \\
\hline 1154 \\
$69.99 \pm 6.81$ \\
$502(58.40)$ \\
$24.17 \pm 3.35$ \\
$135 \pm 16$ \\
$79 \pm 9$ \\
$605(55.4)$ \\
$5.62 \pm 0.93$ \\
$1.92 \pm 1.24$ \\
$1.52 \pm 0.31$ \\
$3.08 \pm 0.59$ \\
$73.13 \pm 17.48$ \\
$87.95 \pm 18.19$ \\
$20(16-26)$ \\
$5.83(5.48-6.24)$ \\
$5.63(5.27-6.01)$ \\
$7.8(6.8-8.9)$ \\
$203.5(130.5-312)$
\end{tabular}

T2DM
784
$69.27 \pm 8.66$
$358(41.60)$
$24.8 \pm 3.85$
$137 \pm 18$
$80 \pm 9$
$381(72.7)$
$5.55 \pm 1.32$
$2.16 \pm 1.58$
$1.37 \pm 0.37$
$3.16 \pm 0.8$
$75.66 \pm 30.37$
$85.94 \pm 21.74$
$21.9(16-30)$
$7.79(7-9.03)$
$7.28(6.25-8.61)$
$12.55(10.4-15.3)$
$227(140-352)$

\begin{tabular}{r}
\hline \multicolumn{1}{c}{$\boldsymbol{P}$} \\
0.054 \\
0.347 \\
$<0.001$ \\
0.001 \\
0.331 \\
$<0.001$ \\
0.191 \\
$<0.001$ \\
$<0.001$ \\
0.032 \\
0.039 \\
0.042 \\
0.003 \\
$<0.001$ \\
$<0.001$ \\
$<0.001$ \\
0.002
\end{tabular}

Data are mean \pm S.D., median (interquartile range) or $n(\%)$

$\mathrm{Cr}$, creatinine; DBP, diastolic blood pressure; eGFR, glomerular filtration rate; HBP, high blood pressure; HDL-c, high-density lipoprotein cholesterol; LDL-c, low-density lipoprotein cholesterol; SBP, systolic blood pressure; TC, total cholesterol; TG, triglyceride.

distribution and age between the two groups $(P=0.347$ and $P=0.054$, respectively). Participants in the T2DM group had significantly higher FBG, postprandial blood glucose, BMI, SBP, triglyceride (TG), low-density lipoprotein cholesterol (LDL-c), and eGFR than those in the non-T2DM group $(P<0.05)$. Serum ferritin levels in the T2DM group were higher than those of the non-T2DM groups (227 (140-352) vs $203.5(130.5-312) \mathrm{ng} / \mathrm{mL}, P<0.05)$.

Serum iron and TF level of participants in the T2DM group were both higher than in the non-T2DM group (serum iron, $21.53 \pm 5.45$ vs $21.53 \pm 4.93 \mu \mathrm{mol} / \mathrm{L}, P=0.017$; serum TF, $2.69 \pm 0.37$ vs $2.42 \pm 0.33 \mathrm{~g} / \mathrm{L}, P<0.001)$. The iron saturation of participants in the T2DM group was also higher than in the non-T2DM group (37.03\% (30.37-49) vs $34.35 \%$ (28.45-40.99), $P=0.007$ ) (Fig. 2).

\section{Human serum ferritin was an independent risk factor for T2DM}

Logistic regression analysis with enter selection was performed to estimate the predictive ability of serum ferritin levels for T2DM. After adjusting for age, sex, BMI, total cholesterol (TC), TG, high-density lipoprotein cholesterol (HDL-c), LDL-c, eGFR, and history of HBP, serum ferritin (the high ferritin group vs the low ferritin group, 1.304 (1.03-1.651), $P<0.05)$ were independent risk factors for T2DM (Table 2).

To eliminate the influence of medication on the results, logistic regression analysis in participants without
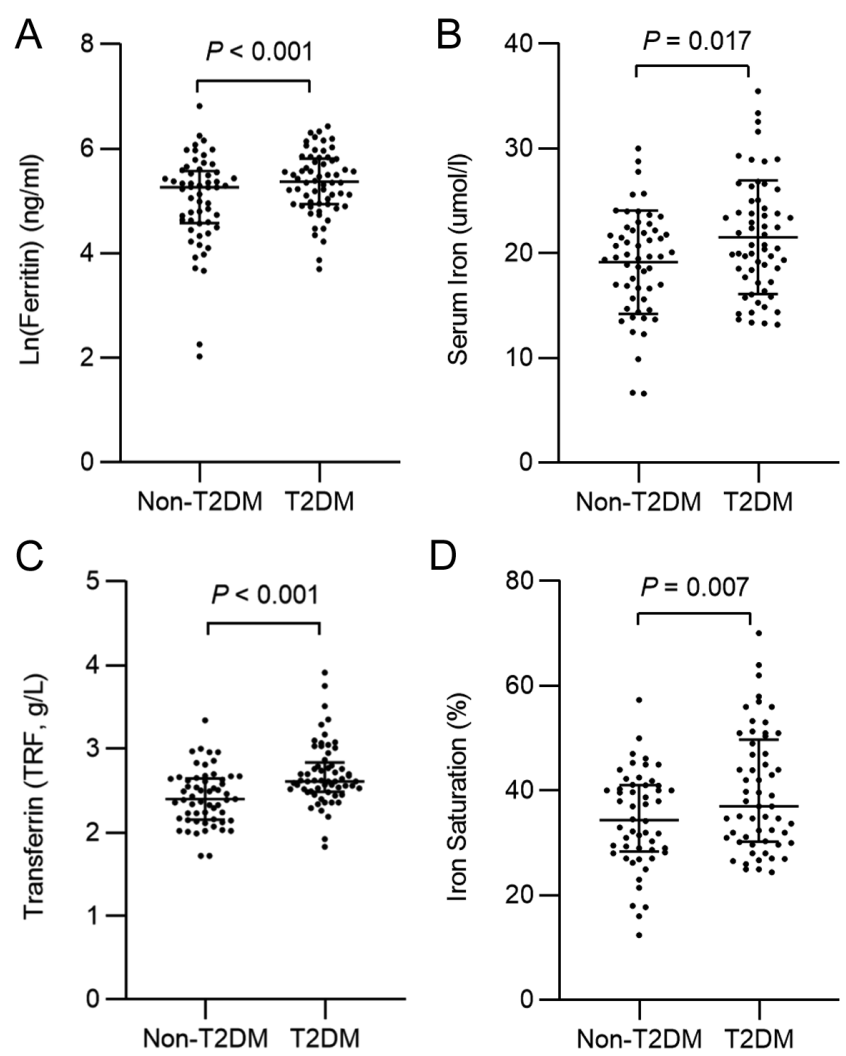

\section{Figure 2}

Serum ferritin, iron, transferrin levels, and iron saturation in participants with and without T2DM. (A and B) Serum ferritin and iron levels in non-T2DM group and T2DM group. (C and D) Serum transferrin level and iron saturation in different groups. Data are the means \pm S.D., median (interquartile range) of two independent experiments. 
Table 2 Logistic regression analysis (enter method) to determine the risk factors for T2DM in the study compared with non-T2DM.

\begin{tabular}{|c|c|c|}
\hline & \multicolumn{2}{|l|}{ Total } \\
\hline & OR $(95 \% \mathrm{CI})$ & $P$ \\
\hline \multicolumn{3}{|l|}{ Gender } \\
\hline Male & Reference & \\
\hline Female & $0.932(0.725-1.198)$ & 0.584 \\
\hline Age & $1.051(1.031-1.072)$ & $<0.001$ \\
\hline BMI & 1.005 (0.97-1.04) & 0.791 \\
\hline $\mathrm{TC}$ & 1.086 (0.799-1.475) & 0.598 \\
\hline TG & $1.1(0.959-1.263)$ & 0.174 \\
\hline $\mathrm{HDL}$ & $0.829(0.484-1.42)$ & 0.496 \\
\hline LDL & 1.342 (0.865-2.08) & 0.189 \\
\hline eGFR & 1.001 (0.995-1.007) & 0.72 \\
\hline \multicolumn{3}{|l|}{ HBP } \\
\hline No & Reference & \\
\hline Yes & $2.012(1.567-2.584)$ & $<0.001$ \\
\hline \multicolumn{3}{|l|}{ Ferritina } \\
\hline 1st & Reference & \\
\hline $2 s t$ & $1.304(1.03-1.651)$ & 0.027 \\
\hline
\end{tabular}

aA median split (based on serum ferritin levels, the cut-off level, $211.5 \mathrm{ng} / \mathrm{mL}$ ) was used to divide the participants into low and high serum ferritin groups.

$\mathrm{Cr}$, creatinine; DBP, diastolic blood pressure; eGFR, glomerular filtration rate; HBP, high blood pressure; HDL-c, high-density lipoprotein cholesterol; LDL-c, low-density lipoprotein cholesterol; SBP, systolic blood pressure; TC, total cholesterol; TG, triglyceride.

medication was performed in the subgroup. The results showed that serum ferritin level was an independent risk factor for T2DM in the subgroups (Table 3).

\section{Effect of STZ administration and HFD on body weight, fasting glucose, and glucose tolerance}

The rats exhibited diabetic profiles with reduced body weight and hyperglycemia (Fig. 3A and B) after STZ and STZ+HFD administration. All rats were subjected to IPGTT at the end of 12th week, and the blood glucose was measured at $0,30,60,90$, and 120 min after administration of $50 \%$ glucose solution ( $2 \mathrm{~g} / \mathrm{kg}$ body weight). A significant increase in the blood glucose of rats in the STZ group was observed at different IPGTT times, as well as in the rats of the HFD+STZ group, accompanied by higher AUCs (area under curve) in the diabetic rats than in the normal rats $(P<0.01)$ (Fig. 3C and D). HOMA-insulin resistance (IR) of rats in the STZ and HFD+STZ groups was significantly higher than that of the control group $(P<0.001)$ (Fig. 3F). The serum insulin levels of rats in the STZ and HFD+STZ groups were both lower than that of the control group $(P<0.01)$ (Fig. 3E).

\section{Effect of STZ administration and HFD on serum iron, serum ferritin, serum transferrin, and serum hepcidin}

The serum iron levels of rats in both the STZ and HFD + STZ groups were increased compared to the control group (STZ group vs control group, $46.12 \pm 14.38$ vs $40.28 \pm 4.96$, $P=0.369 ; \mathrm{HFD}+\mathrm{STZ}$ vs control group, $70.11 \pm 9.57$ vs $40.28 \pm 4.96, P<0.001$, Fig. 4B). The changes in serum

Table 3 Logistic regression analysis (enter method) was performed in the subgroup to determine the risk factors for T2DM in participants without medication.

\begin{tabular}{|c|c|c|c|c|c|c|}
\hline & \multicolumn{2}{|c|}{$\begin{array}{l}\text { Participants without } \\
\text { antihyperglycemic therapy }\end{array}$} & \multicolumn{2}{|c|}{$\begin{array}{l}\text { Participants without } \\
\text { antihypertensive therapy }\end{array}$} & \multicolumn{2}{|c|}{$\begin{array}{l}\text { Participants without lipid } \\
\text { lowering therapy }\end{array}$} \\
\hline & OR $(95 \% \mathrm{Cl})$ & $P$ & OR $(95 \% \mathrm{Cl})$ & $P$ & OR $(95 \% \mathrm{Cl})$ & $P$ \\
\hline \multicolumn{7}{|l|}{ Gender } \\
\hline Male & Reference & & & & & \\
\hline Female & 0.787 (0.557-1.111) & 0.173 & $1.249(0.825-1.891)$ & 0.294 & 0.927 (0.72-1.195) & 0.561 \\
\hline Age & $1.052(1.025-1.081)$ & $<0.001$ & 1.08 (1.045-1.116) & $<0.001$ & 1.053 (1.032-1.074) & $<0.001$ \\
\hline $\mathrm{BMI}$ & $1.031(0.984-1.081)$ & 0.203 & $1.023(0.966-1.083)$ & 0.44 & 1.007 (0.972-1.043) & 0.711 \\
\hline $\mathrm{TC}$ & $1.355(0.899-2.042)$ & 0.147 & $0.853(0.494-1.472)$ & 0.567 & 1.09 (0.801-1.485) & 0.582 \\
\hline TG & $1.095(0.921-1.301)$ & 0.305 & 1.607 (1.194-2.163) & 0.002 & $1.11(0.967-1.275)$ & 0.139 \\
\hline HDL & $0.654(0.315-1.359)$ & 0.255 & $1.808(0.716-4.564)$ & 0.21 & 0.875 (0.509-1.505) & 0.629 \\
\hline LDL & $0.998(0.556-1.793)$ & 0.995 & 1.868 (0.879-3.97) & 0.104 & 1.35 (0.868-2.099) & 0.183 \\
\hline eGFR & 1.004 (0.995-1.012) & 0.397 & 0.998 (0.988-1.009) & 0.769 & 1.001 (0.995-1.007) & 0.747 \\
\hline \multicolumn{7}{|l|}{ HBP } \\
\hline No & Reference & & & & & \\
\hline Yes & $1.466(1.05-2.046)$ & 0.025 & 2.007 (1.272-3.168) & 0.003 & $1.968(1.529-2.533)$ & $<0.001$ \\
\hline \multicolumn{7}{|l|}{ Ferritin } \\
\hline $1^{\text {st }}$ & Reference & & & & & \\
\hline $2 s t$ & 1.477 (1.072-2.034) & 0.017 & 1.521 (1.034-2.237) & 0.033 & 1.304 (1.028-1.653) & 0.029 \\
\hline
\end{tabular}

Cr, creatinine; DBP, diastolic blood pressure; eGFR, glomerular filtration rate; HBP, high blood pressure; HDL-c, high-density lipoprotein cholesterol; LDL-c, low-density lipoprotein cholesterol; SBP, systolic blood pressure; TC, total cholesterol; TG, triglyceride.

https://ec.bioscientifica.com https://doi.org/10.1530/EC-21-0316 (c) 2021 The authors Published by Bioscientifica Ltd

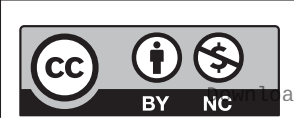

This work is licensed under a Creative Commons Attribution-NonCommercial 4.0 International License. ded from Bioscientifica.com at $04 / 26 / 2023$ 02:07:27AM via free access 

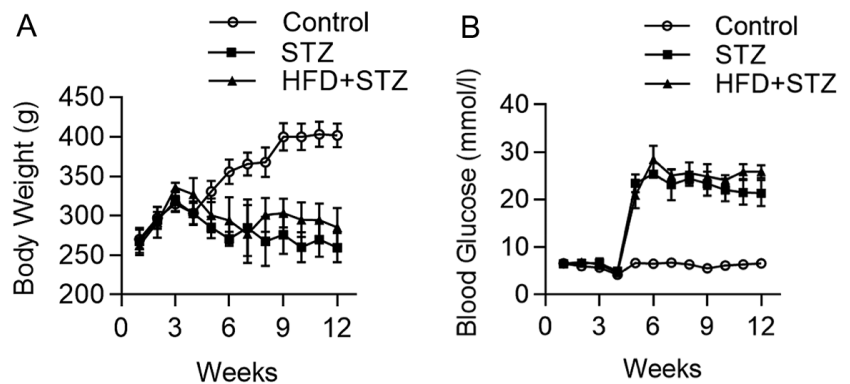

C
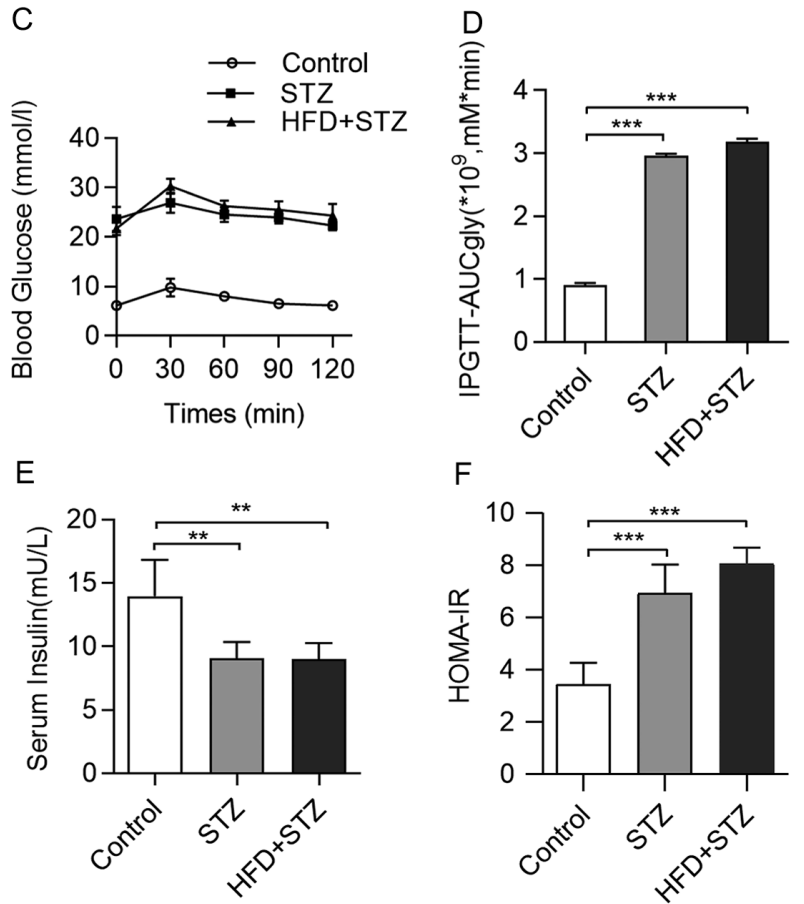

$\mathrm{F}$

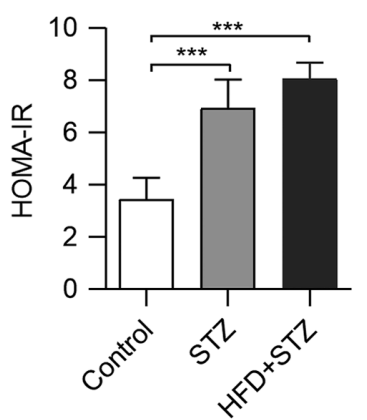

Figure 3

Bodyweight, blood glucose, IPGTT, serum insulin, and HOMA-IR in rats of different groups. (A and B) Bodyweight and blood glucose were monitored once weekly throughout the experiment $(n=6)$. (C) Blood glucose was measured during the last week after glucose injections $(n=6)$. (D) AUC (area under curve) of GTT ( $n=6)$. (E and F) HOMA-IR and serum insulin were analyzed at the end of the experiment $(n=6)$. HFD+STZ: high-fat diet (HFD) + STZ; STZ: normal diet + STZ; control: normal diet. Data are expressed as means \pm s.D. for three groups of six rats. One-way ANOVA, followed by LSD $t$ and SNK post hoc test, was performed to analyze the difference between the three groups. Differences were considered as significant at $P<0.05$. *Significantly different from controls, $* P<0.05 ; * * P<0.01 ; * * * P<0.001$.

ferritin (STZ group vs control group, $4.57 \pm 0.10$ vs $4.44 \pm 0.14$ $\mathrm{ng} / \mathrm{mL}, P=0.100 ; \mathrm{HFD}+\mathrm{STZ}$ vs control group, $4.59 \pm 0.06$ vs $4.44 \pm 0.14 \mathrm{ng} / \mathrm{mL}, P=0.03,4 \mathrm{~A}$ ) and serum TF (STZ group vs control group, $6.89 \pm 0.28$ vs $6.51 \pm 0.28 \mathrm{mg} / \mathrm{L}, P=0.037$; HFD + STZ vs control group, $6.93 \pm 0.27$ vs $6.51 \pm 0.28$, $P=0.024, \mathrm{mg} / \mathrm{L}$, Fig. $4 \mathrm{C}$ ) were similar to that of iron. Due to the importance of HAMP in iron regulation, we detected the serum HAMP levels in each group. The serum HAMP level of rats both in the STZ and HFD+STZ groups was decreased compared to the control group (STZ group vs control group, $7.61 \pm 1.38$ vs $8.92 \pm 1.05 \mu \mathrm{g} / \mathrm{L}, P=0.369$; HFD + STZ vs control group, $7.15 \pm 0.84$ vs $8.92 \pm 1.05 \mu \mathrm{g} / \mathrm{L}$, $P=0.009$, Fig. 4D).

\section{Alteration of hepatic TFR2 protein level in different animal groups}

To detect the protein expression of TFR2, we performed WB. The rats in the HFD+STZ group exhibited a $40 \%$ reduction in liver TFR2 expression as compared to the control group $(P<0.05)$, and the rats in the STZ group showed a $12 \%$ reduction compared to the control group $(P>0.05$, Fig. 4E and F). The correlation between liver TFR2 and serum insulin levels was explored, and a positive association was found ( $\mathrm{r}=0.649, P=0.004$, Fig. $4 \mathrm{G})$.

\section{Discussion}

In this study, we demonstrated iron overload in patients with T2DM, manifested as an elevation of serum ferritin levels, thereby reflecting tissue iron stores. Furthermore, we also confirmed that iron overload presented with increased serum iron and ferritin levels in STZ-induced diabetic rats were fed with an HFD. Given the importance of HAMP in iron homeostasis, this study verified a reduction in serum HAMP levels in diabetic rats. More importantly, the study indicated a significantly reduced TFR2 protein level in the liver of T2DM rats, suggesting that decreased TFR2 may play an important role in iron overload in T2DM.

Iron overload is associated with T2DM, including its development and complications (1, 2, 3). However, the underlying mechanisms of iron metabolism disorders in T2DM are still unclear. The liver is the major iron storage organ that synthesizes numerous iron-related genes encoding TFR2 and HAMP as the main regulators of iron metabolism $(7,14,15,16,17)$; therefore, the liver is the key regulator of iron homeostasis. Decreased serum proHAMP levels were recently reported in T2DM patients (18), but whether TFR2 has changed is still unknown. We hypothesized that TFR2 may be reduced in patients with T2DM, accompanied by elevated serum ferritin levels.

Serum ferritin levels were significantly higher in T2DM participants than in non-diabetic participants. This finding is in agreement with that of previous studies (19, $20,21)$. In this study, we verified that serum ferritin level was an independent risk factor for T2DM.

To further explore the underlying mechanisms of iron metabolism disorder in T2DM, we demonstrated iron metabolism disorder in STZ-induced diabetic rats fed

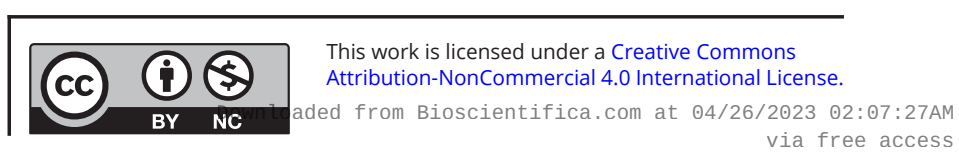


A

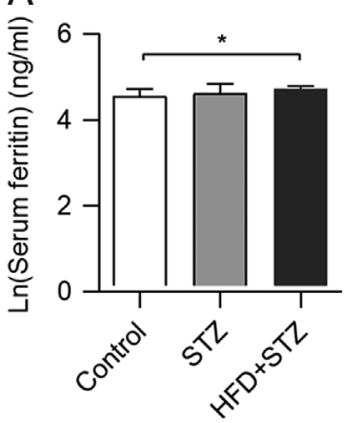

E

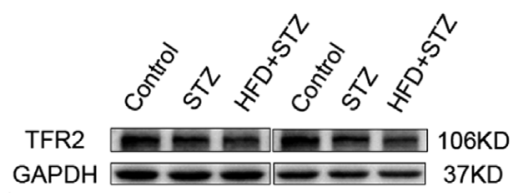

B

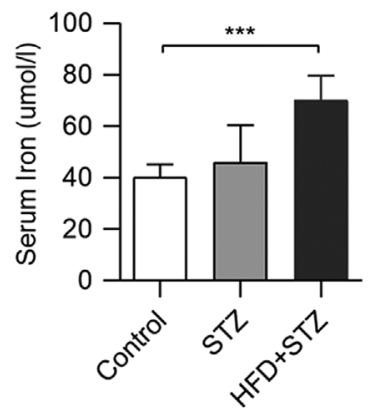

C

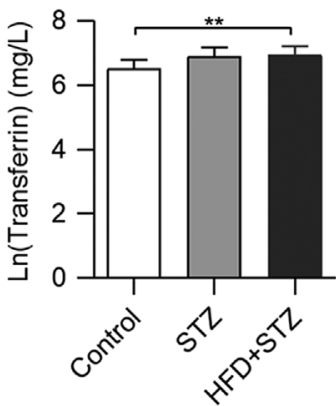

D

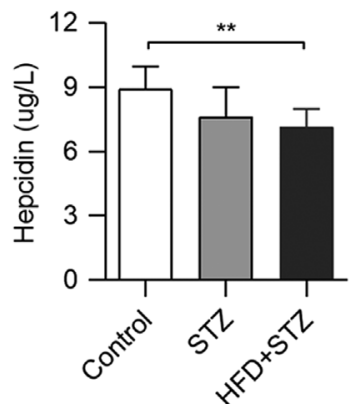

$\mathrm{F}$

G
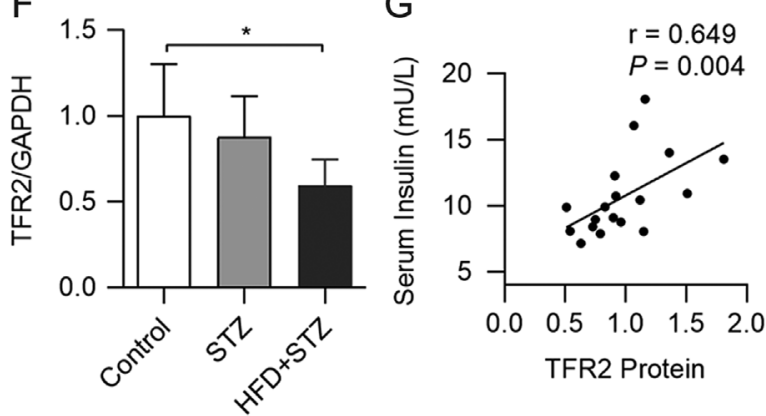

Figure 4

Effect of STZ administration with and without HFD on serum iron, serum ferritin, and serum hepcidin in rats and expression of transferrin receptor 2 (TFR2) in rats of different group. (A, C, and D) Serum ferritin, transferrin, and hepcidin levels of the rats were analyzed using ELISA kits ( $n=6)$. (B) Serum iron levels of each rat using colorimetric analysis kits $(n=6)$. (E and F) The protein levels of hepatic TFR2 were analyzed using Western blot (WB) analysis $(n=4)$. (G) The correlation between liver TFR2 level and serum insulin level was explored. HFD + STZ: high-fat diet (HFD) + STZ; STZ: normal diet + STZ; control: normal diet. Data are expressed as means \pm s.D. for three groups of six rats. One-way ANOVA, followed by LSD t and SNK post hoc test, was performed to analyze the difference between the three groups. Differences were considered as significant at $P<0.05$. * Significantly different from controls, $* P<0.05 ; * * P<0.01 ; * * * P<0.001$.

with an HFD, as elucidated by the elevations in the serum ferritin and serum iron levels. These results concur with those of previous studies $(22,23,24)$. Saravanan et al. (23) showed that serum iron was increased in STZ rats, and Dogukan et al. (17) reported that STZ injection following HFD intake markedly increased hepatic and serum iron levels. There is little consensus on the underlying mechanisms of iron metabolism disorders in T2DM. However, Wang et al. found that HAMP plays an important role in diabetic rats. In this study, serum HAMP levels were significantly reduced in HFD +STZ rats.

Some studies have demonstrated that mutations in the TFR2 gene cause iron overload in the body $(25,26)$. Hence, we investigated the changes in TFR2 in diabetic rats and found a reduction in the level of TFR2 protein in T2DM rats. To the best of our knowledge, no other study has reported reduced TFR2 in T2DM rats. TFR2 expression is limited predominantly to hepatocytes and is not regulated by intracellular iron, which indicates that TFR2 may function, not principally in cellular iron uptake and delivery, but rather in systemic iron homeostasis.
However, further experiments are necessary to verify this finding.

There were some limitations to this study. First, this was a cross-sectional study. Although we tried to avoid possible confounding factors, due to the inherent limitations of the cross-sectional study, there were some factors which we were unable to avoid. In the future, we will attempt to conduct cohort studies. Secondly, further research in humans and animal studies should be performed to clarify the pathway for decreased TFR2.

\section{Conclusion}

In conclusion, our study has demonstrated an elevation of serum ferritin levels in T2DM patients. Moreover, serum ferritin level was an independent risk factor for T2DM. We have also shown evidence that serum HAMP level and liver TFR2 in diabetic rats were lower than those in the control group, which suggests that TFR2 may play an important role in hyperferritinemia in T2DM, implying a potential therapeutic target for iron overload in T2DM.
This work is licensed under a Creative Commons Attribution-NonCommercial 4.0 International License. ded from Bioscientifica.com at 04/26/2023 02:07:27AM via free access 


\section{Declaration of interest}

The authors declare that there is no conflict of interest that could be perceived as prejudicing the impartiality of the research reported.

\section{Funding}

This study was funded by Shanghai Minhang District Natural Science Foundation (grant number: 2019MHZ066), Medical Key Faculty Foundation of Shanghai (ZK2019B15), Shanghai Fifth People's Hospital Key Project (grant number: 2018WYZD04), and Shanghai Fifth People's Hospital Incubation Project (grant number: 2018WYFY02). Health Profession Clinical Research Funds of Shanghai Municipal Health Commission (Grant number: 201940295).

\section{Ethical approval}

Approval from the Animal Ethics Committee of the Shanghai Jiao Tong University in Shanghai, China was obtained (A2015072). This analysis involving human participants was approved by the Independent Ethics Committee of the Fifth People's Hospital of Shanghai, Fudan University (2010-024). Consent has been obtained from each patient or subject after full explanation of the purpose and nature of all procedures used.

\section{References}

1 Rajpathak SN, Crandall JP, Wylie-Rosett J, Kabat GC, Rohan TE \& $\mathrm{Hu}$ FB. The role of iron in type 2 diabetes in humans. Biochimica et Biophysica Acta 20091790 671-681. (https://doi.org/10.1016/j. bbagen.2008.04.005)

2 Zheng X, Jiang T, Wu H, Zhu D, Wang L, Qi R, Li M \& Ling C. Hepatic iron stores are increased as assessed by magnetic resonance imaging in a Chinese population with altered glucose homeostasis. American Journal of Clinical Nutrition 201194 1012-1019. (https://doi. org/10.3945/ajcn.111.015743)

3 Chen L, Li Y, Zhang F, Zhang S, Zhou X \& Ji L. Association of serum ferritin levels with metabolic syndrome and insulin resistance in a Chinese population. Journal of Diabetes and its Complications 201731 364-368. (https://doi.org/10.1016/j.jdiacomp.2016.06.018)

4 Camaschella C, Roetto A, Calì A, De Gobbi M, Garozzo G, Carella M, Majorano N, Totaro A \& Gasparini P. The gene TFR2 is mutated in a new type of haemochromatosis mapping to 7q22. Nature Genetics 2000 25 14-15. (https://doi.org/10.1038/75534)

5 Cooksey RC, Jones D, Gabrielsen S, Huang J, Simcox JA, Luo B, Soesanto Y, Rienhoff H, Abel ED \& McClain DA. Dietary iron restriction or iron chelation protects from diabetes and loss of betacell function in the obese (ob/ob lep-/-) mouse. American Journal of Physiology: Endocrinology and Metabolism 2010298 E1236-E1243. (https://doi.org/10.1152/ajpendo.00022.2010)

6 Van Campenhout A, Van Campenhout C, Lagrou AR, Abrams P, Moorkens G, Van Gaal L \& Manuel-y-Keenoy B. Impact of diabetes mellitus on the relationships between iron-, inflammatory- and oxidative stress status. Diabetes/Metabolism Research and Reviews 2006 22 444-454. (https://doi.org/10.1002/dmrr.635)

7 Wang H, Li H, Jiang X, Shi W, Shen Z \& Li M. Hepcidin is directly regulated by insulin and plays an important role in iron overload in streptozotocin-induced diabetic rats. Diabetes 201463 1506-1518. (https://doi.org/10.2337/db13-1195)

8 Ribeiro S, Garrido P, Fernandes J, Rocha-Pereira P, Costa E, Belo L, Reis F \& Santos-Silva A. Liver iron is a major regulator of hepcidin gene expression via BMP/SMAD pathway in a rat model of chronic renal failure under treatment with high rHuEPO doses. BioFactors 201642 296-306. (https://doi.org/10.1002/biof.1275)
9 Rishi G, Wallace DF \& Subramaniam VN. Hepcidin: regulation of the master iron regulator. Bioscience Reports 201535 e00192. (https://doi. org/10.1042/BSR20150014)

10 Worthen CA \& Enns CA. The role of hepatic transferrin receptor 2 in the regulation of iron homeostasis in the body. Frontiers in Pharmacology 20145 34. (https://doi.org/10.3389/fphar.2014.00034)

11 Lin L, Valore EV, Nemeth E, Goodnough JB, Gabayan V \& Ganz T. Iron transferrin regulates hepcidin synthesis in primary hepatocyte culture through hemojuvelin and BMP2/4. Blood 2007110 2182-2189. (https://doi.org/10.1182/blood-2007-04-087593)

12 The Expert Committee on the Diagnosis and Classification of Diabetes Mellitus. Report of the expert committee on the diagnosis and classification of diabetes mellitus. Diabetes Care 199720 1183-1197. (https://doi.org/10.2337/diacare.20.7.1183)

13 Stevens LA, Coresh J, Feldman HI, Greene T, Lash JP, Nelson RG, Rahman M, Deysher AE, Zhang YL, Schmid CH, et al. Evaluation of the modification of diet in renal disease study equation in a large diverse population. Journal of the American Society of Nephrology 200718 2749-2757. (https://doi.org/10.1681/ASN.2007020199)

14 Yu FJ, Huang MC, Chang WT, Chung HF, Wu CY, Shin SJ \& Hsu CC. Increased ferritin concentrations correlate with insulin resistance in female type 2 diabetic patients. Annals of Nutrition and Metabolism 201261 32-40. (https://doi.org/10.1159/000339265)

15 Soheilykhah S, Mojibian M \& Jannati Moghadam M. Serum ferritin concentration in early pregnancy and risk of subsequent development of gestational diabetes: a prospective study. International Journal of Reproductive Biomedicine 201715 155-160.

16 Hughes EA, Patel JV, Bredow Z, Gill PS, Chackathayil J, Agaoglu ES, Flinders P \& Mirrielees R. Ferritin as a risk factor for glucose intolerance amongst men and women originating from the Indian subcontinent. International Journal of Endocrinology 20152015924387. (https://doi.org/10.1155/2015/924387)

17 Dogukan A, Sahin N, Tuzcu M, Juturu V, Orhan C, Onderci M, Komorowski J \& Sahin K. The effects of chromium histidinate on mineral status of serum and tissue in fat-fed and streptozotocintreated type II diabetic rats. Biological Trace Element Research 2009131 124-132. (https://doi.org/10.1007/s12011-009-8351-8)

18 Aso Y, Takebayashi K, Wakabayashi S, Momobayashi A, Sugawara N, Terasawa T, Naruse R, Hara K, Suetsugu M, Morita K, et al. Relation between serum high molecular weight adiponectin and serum ferritin or prohepcidin in patients with type 2 diabetes. Diabetes Research and Clinical Practice 201090 250-255. (https://doi.org/10.1016/j. diabres.2010.09.008)

19 Aljwaid H, White DL, Collard KJ, Moody AJ \& Pinkney JH. Nontransferrin-bound iron is associated with biomarkers of oxidative stress, inflammation and endothelial dysfunction in type 2 diabetes. Journal of Diabetes and its Complications 2015 29 943-949. (https://doi. org/10.1016/j.jdiacomp.2015.05.017)

20 Jehn M, Clark JM \& Guallar E. Serum ferritin and risk of the metabolic syndrome in U.S. adults. Diabetes Care 200427 2422-2428. (https:// doi.org/10.2337/diacare.27.10.2422)

21 Kim CH, Kim HK, Bae SJ, Park JY \& Lee KU. Association of elevated serum ferritin concentration with insulin resistance and impaired glucose metabolism in Korean men and women. Metabolism: Clinical and Experimental $201160414-420$. (https://doi.org/10.1016/j. metabol.2010.03.007)

22 Silva M, de Brito Magalhaes CL, de Paula Oliveira R, Silva ME \& Pedrosa ML. Differential expression of iron metabolism proteins in diabetic and diabetic iron-supplemented rat liver. Journal of Biochemical and Molecular Toxicology 201226 123-129. (https://doi. org/10.1002/jbt.20418)

23 Saravanan G, Ponmurugan P \& Begum MS. Effect of S-allylcysteine, a sulphur containing amino acid on iron metabolism in streptozotocin induced diabetic rats. Journal of Trace Elements in Medicine and Biology 201327 143-147. (https://doi.org/10.1016/j.jtemb.2012.07.009) https://ec.bioscientifica.com https://doi.org/10.1530/EC-21-0316 (c) 2021 The authors Published by Bioscientifica Ltd

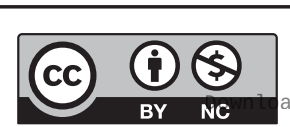

This work is licensed under a Creative Commons Attribution-NonCommercial 4.0 International License. ded from Bioscientifica.com at 04/26/2023 02:07:27AM 
24 Silvestri L, Nai A, Pagani A \& Camaschella C. The extrahepatic role of TFR2 in iron homeostasis. Frontiers in Pharmacology 20145 93. (https:// doi.org/10.3389/fphar.2014.00093)

25 Gao J, Chen J, Kramer M, Tsukamoto H, Zhang AS \& Enns CA. Interaction of the hereditary hemochromatosis protein HFE with transferrin receptor
2 is required for transferrin-induced hepcidin expression. Cell Metabolism 20099 217-227. (https://doi.org/10.1016/j.cmet.2009.01.010)

26 Hentze MW, Muckenthaler MU, Galy B \& Camaschella C. Two to tango: regulation of mammalian iron metabolism. Cell 2010142 24-38. (https://doi.org/10.1016/j.cell.2010.06.028)

Received in final form 10 October 2021

Accepted 2 November 2021

Accepted Manuscript published online 2 November 2021
This work is licensed under a Creative Commons Attribution-NonCommercial 4.0 International License. 